\title{
Verticillium tricorpus causing lettuce wilt in Japan differs genetically from California lettuce isolates
}

\author{
Toshiyuki Usami · Takeshi Kanto $\cdot$ Patrik Inderbitzin • Mizuho Itoh • \\ Gan Kisaki - Yoshiyuki Ebihara - Wataru Suda - Yoshimiki Amemiya • \\ Krishna V. Subbarao
}

Received: 24 August 2010/Accepted: 8 October 2010/Published online: 10 November 2010

(C) The Author(s) 2010. This article is published with open access at Springerlink.com

\begin{abstract}
In January 2002, Verticillium wilt of lettuce (Lactuca sativa L.) caused by Verticillium tricorpus occurred in upland paddy fields in Hyogo Prefecture for the first time in Japan. This fungal species was first isolated from lettuce in California, USA. In the present study, the genetic relationships between the American and Japanese isolates of $V$. tricorpus from lettuce were analyzed to determine whether the pathogen could have migrated to Japan from the USA, the major lettuce-seed supplier for Japan. Nucleotide sequences of the rDNA internal transcribed spacer regions, as well as the genes coding for translation elongation factor 1-alpha and RNA polymerase II were compared among American and Japanese V. tricorpus isolates from lettuce. The Japanese isolates of $V$. tricorpus were distinct from the American. Random
\end{abstract}

The nucleotide sequence data reported are available in the DDBJ/ EMBL/GenBank databases as accessions AB545875-AB545895, AB545897-AB545906, AB545911-AB545921, AB545923, and AB548747-AB548758.

Electronic supplementary material The online version of this article (doi:10.1007/s10327-010-0282-x) contains supplementary material, which is available to authorized users.

T. Usami $(\bowtie) \cdot$ M. Itoh · Y. Amemiya

Graduate School of Horticulture, Chiba University,

648 Matsudo, Matsudo, Chiba 271-8510, Japan

e-mail: usami@faculty.chiba-u.jp

T. Kanto

Hyogo Prefectural Technology Center for Agriculture,

Forestry and Fisheries, Kasai, Hyogo 679-0098, Japan

P. Inderbitzin - K. V. Subbarao

Department of Plant Pathology, University of California,

Davis, c/o US Agricultural Research Station, Salinas,

CA 93905, USA amplified polymorphic DNA analyses also supported this conclusion. These results demonstrated that Verticillium wilt on lettuce caused by $V$. tricorpus in Japan was not related to the isolates causing the disease in California.

Keywords Verticillium tricorpus . Verticillium wilt . Lettuce $\cdot$ Phylogenetic analysis · Random amplified polymorphic DNA (RAPD)

\section{Introduction}

In January 2002, Verticillium wilt of lettuce (Lactuca sativa $\mathrm{L}$.) occurred in upland paddy fields in Awaji Island, Hyogo Prefecture, for the first time in Japan (Kanto et al. 2003). The disease spread to neighboring Kagawa Prefecture within a few years. Phytopathogenic species of Verticillium cause Verticillium wilt in a variety of hosts (Pegg and Brady 2002). These species are identified primarily by the resting structures (Isaac 1967; Smith 1965) that they produce in culture; Verticillium dahliae Kleb., produces microsclerotia, and V. albo-atrum Reinke and Berthold, produces dark resting mycelia. In contrast, V. tricorpus I. Isaac produces microsclerotia, dark resting mycelia, and

\section{G. Kisaki}

Kagawa Prefectural Agricultural Experiment Station,

Takamatsu, Kagawa 761-8078, Japan

Y. Ebihara

Chiba Prefectural Agriculture and Forestry Research Center, Southern Horticulture Institute, Tateyama, Chiba 294-0014, Japan

W. Suda

Graduate School of Frontier Sciences, The University of Tokyo, Kashiwa, Chiba 277-8561, Japan 
chlamydospores. Verticillium species isolated from diseased lettuce on Awaji Island formed all three resting structures in culture. Optimal temperature for growth of this fungus was between 20 and $22^{\circ} \mathrm{C}$ with the mature cultures developing yellow pigmentation. From these morphological and cultural characteristics, Kanto et al. (2005) identified the pathogen from lettuce as V. tricorpus.

Although Isaac (1953) described V. tricorpus in 1953, this species was not reported in Japan until 1998. In 1998, Ebihara et al. (2003) first isolated V. tricorpus from potato tubers in Japan. However, these isolates were nonpathogenic on potato, Chinese cabbage, eggplant, green pepper, larkspur, parsley, snapdragon, soybean, tobacco, and tomato. Later, Chikuo et al. (2000) found that V. tricorpus isolates were pathogenic on delphinium. The Verticillium wilt outbreak on lettuce in Hyogo Prefecture in 2002 caused by $V$. tricorpus is only the second incident of the disease in Japan; thus, besides being relatively new to Japan, $V$. tricorpus has also been relatively rare.

The first report of $V$. tricorpus from lettuce was from California in 1997, where it was judged to be weakly pathogenic (Qin et al. 2008). The United States is a principal lettuce-seed producing country for Japan. Contaminated lettuce seed can serve as inoculum for Verticillium wilt caused by the related species $V$. dahliae (Vallad et al. 2005). This pathogen can also be transported across long distances on seed (Atallah et al. 2010). It is thus conceivable that the 2002 lettuce wilt outbreak in Japan might have been caused by $V$. tricorpus introduced with contaminated seed from the USA. To address this question, we investigated the genetic similarity of $V$. tricorpus lettuce isolates from the USA and from Japan, using phylogenetic analyses based on three loci as well as random amplified polymorphic DNA (RAPD) fingerprinting.

\section{Materials and methods}

Fungal strains and culture

Table 1 presents strains of $V$. tricorpus used in this study. Each strain was maintained on potato sucrose agar [potato broth containing $2 \%(\mathrm{w} / \mathrm{v})$ sucrose and $2 \%(\mathrm{w} / \mathrm{v})$ agar] slants. For morphological observations using microscopy, strains were cultured on potato sucrose agar plate and incubated at $20^{\circ} \mathrm{C}$ for 2 or 3 weeks.

Pathogenicity test

Strain MIH001 was subcultured for 1 week in potato sucrose broth [potato broth containing $2 \%(\mathrm{w} / \mathrm{v})$ sucrose] and incubated in an orbital shaker at $25^{\circ} \mathrm{C}$. After filtering through cheesecloth, budding spores were collected by
Table 1 Isolates of Verticillium tricorpus used for this study

\begin{tabular}{llll}
\hline Strain & Original host & Geographical location & Year isolated \\
\hline MIH001 & Lettuce & Hyogo, Japan & 2002 \\
MIH003 & Lettuce & Hyogo, Japan & 2002 \\
Shichi6 & Lettuce & Hyogo, Japan & 2007 \\
Shichi12 & Lettuce & Hyogo, Japan & 2007 \\
KNty-2-2 & Lettuce & Kagawa, Japan & 2005 \\
eLTS-1 & Lettuce & Chiba, Japan & 2000 \\
eLTS-2 & Lettuce & Chiba, Japan & 2000 \\
CE99Vt2 & Lettuce & Chiba, Japan & 1999 \\
Ls.183 $^{\text {a }}$ & Lettuce & California, USA & 1997 \\
Ls.432 $^{\text {a }}$ & Lettuce & California, USA & 2001 \\
Ls.441 $^{\text {a }}$ & Lettuce & California, USA & 2001 \\
Ls.442 $^{\text {a }}$ & Lettuce & California, USA & 2001 \\
Ls.443 $^{\text {a }}$ & Lettuce & California, USA & 2001 \\
NO-1 $_{\text {MAFF 712235 }}$ & Delphinium & Kagawa, Japan & 2008 \\
MAFF 712236 $^{\text {b }}$ & Delphinium & Miyagi, Japan & 1999 \\
CE98Vt1 $^{\text {c }}$ & Potato & Miyagi, Japan & 1999 \\
CE20VtLe3 $^{\text {c }}$ & Tomato & Chiba, Japan & 2000 \\
NBRC 31025 $^{\text {d,e }}$ & Unknown & UK & Unknown \\
\hline
\end{tabular}

${ }^{a}$ Strains reported by Qin et al. (2008)

b Strains from National Institute of Agrobiological Sciences (NIAS) Genebank, Japan

c Strains reported by Ebihara et al. (2003)

d Strain from National Institute of Technology and Evaluation (NITE)-Biological Resource Center, Japan

e According to database of the NITE-Biological Resource Center, this strain was from I. Isaac who proposed V. tricorpus as a species

centrifugation for $5 \min (3000 \times g)$. Fifty milliliters of spore suspension $\left(5 \times 10^{6}\right.$ spores $/ \mathrm{mL}$ distilled water) was poured into each plastic pot containing a 4-week-old lettuce seedling. Lettuce cultivars Logic (Yokohama Nursery Co., Yokohama, Kanagawa, Japan), Cisco (Takii \& Co., Kyoto, Japan), and Santos-2 (Fujii' Seed Co., Osaka, Japan) were used for experiments 1 and 2, experiments 3 and 4, and experiments 5 and 6 , respectively. For inoculation of experiments 1 and 2,14 and 7 seedlings, for experiments 3 and 4, 12 and 7 seedlings, and for experiments 5 and 6, 12 and 4 seedlings, respectively, were used. For each experiment, a similar number of uninoculated seedlings were maintained as controls. Inoculated and uninoculated plants were maintained in a growth chamber at $18^{\circ} \mathrm{C}$ and a $12-\mathrm{h}$ photoperiod. The plants were watered enough everyday to maintain soil moisture. Wilting of leaves and vascular browning in cross or vertical sections of the taproot and stem were evaluated at $25,33,28,33,18$, and 33 days after inoculation in experiments 1 through 6 , respectively. Wilting of leaves was estimated on a scale of $0-4$ where $0=$ no wilting, $1=$ lower leaves wilted, $2=$ middle leaves wilted, 
3 = upper leaves wilted, with or without yellowing, and $4=$ systemic wilt or death of seedling. After surface sterilization by soaking in $70 \%(\mathrm{w} / \mathrm{w})$ ethanol (for $30 \mathrm{~s}$ ) and $0.5 \%(\mathrm{w} / \mathrm{w})$ sodium hypochlorite (for $3 \mathrm{~min}$ ), discolored stem sections were put on a water agar plate for reisolation of the pathogen from symptomatic plants. Wilt incidence was calculated as the ratio of the number of wilted plants to the total number of plants inoculated and expressed as a percentage.

Polymerase chain reaction and sequencing

Genomic DNA of each fungal strain was extracted using a standard phenol-chloroform extraction method (Usami et al. 2002, 2005) or a QIAamp Tissue Kit (Qiagen GmbH, Hilden, Germany). The genomic region of ribosomal DNA ITS1-5.8S-ITS2 was amplified using PCR primers ITS1 and ITS4 (White et al. 1990). A part of the translation elongation factor 1-alpha gene $(E F 1 \alpha)$ was amplified using primers EF1-983F and EF1-1567R (Rehner and Buckley 2005). The DNA-dependent RNA polymerase II largest subunit gene $(r p b l)$ was partially amplified using PCR primers Vrpb1F and Vrpb1R, which we designed from the sequence of $V$. tricorpus (AY555904) reported by Pantou et al. (2005). Nucleotide sequences of primers are presented in Table S1 in Electronic Supplementary Material. For amplification of each genomic region, a $20-\mu \mathrm{L}$ PCR mixture containing $20 \mathrm{ng}$ fungal genomic DNA, $100 \mathrm{pmol}$ of each primer, and $10 \mu \mathrm{L}$ of Premix Ex Taq Hot Start Version (Takara Bio Inc., Otsu, Shiga, Japan) was prepared. The following PCR program was used for amplification of the ITS1-5.8S-ITS2 region: $95^{\circ} \mathrm{C}$ for $5 \mathrm{~min}$; 40 cycles of $95^{\circ} \mathrm{C}$ for $1 \mathrm{~min}, 53^{\circ} \mathrm{C}$ for $1 \mathrm{~min}$, and $72^{\circ} \mathrm{C}$ for $1 \mathrm{~min}$; and $72^{\circ} \mathrm{C}$ for $5 \mathrm{~min}$. The following PCR program was used for amplification of $E F 1 \alpha$ and $r p b l: 95^{\circ} \mathrm{C}$ for $5 \mathrm{~min} ; 40$ cycles of $95^{\circ} \mathrm{C}$ for $1 \mathrm{~min}, 60^{\circ} \mathrm{C}$ for $1 \mathrm{~min}$, and $72^{\circ} \mathrm{C}$ for $1 \mathrm{~min}$; and $72^{\circ} \mathrm{C}$ for $5 \mathrm{~min}$. The nucleotide sequence of each PCR product was analyzed using BigDye Terminator v3.1 Cycle Sequencing Kit (Life Technologies, Carlsbad, CA, USA) and an auto-sequencer (Applied Biosystems 3730 DNA Analyzer, Life Technologies).

\section{Phylogenetic analysis}

In addition to the nucleotide sequences that were determined in this study, sequences of the ITS1-5.8S-ITS2 region of V. tricorpus strains Ls.183 (GQ336717), Ls. 443 (GQ336792), CE98Vt1 (AB353343), CE20VtLe3 (AB353344), and $V$. dahliae TV103 (AB353345) were downloaded from the GenBank/EMBL/DDBJ database (http://www.ddbj.nig.ac. jp/index-e.html) and included in the phylogenetic analyses. Combined sequences of ITS1-5.8S-ITS2, EF1 $\alpha$, and rpbl regions were aligned using the CLUSTAL W program (http://clustalw.ddbj.nig.ac.jp/top-e.html) (Thompson et al. 1994) with default parameters. A maximum parsimony (MP) tree was constructed with the close-neighbor interchange method (search level $=3$, random addition with 10 replications) and treating gaps as missing data, using the software MEGA 4 (http://www.megasoftware.net/) (Tamura et al. 2007). A neighbor-joining (NJ) tree was constructed using maximum composite likelihood. Bootstrap analyses for 1000 replicates were performed on each tree.

\section{RAPD analysis}

For RAPD analysis, 16 primers included in the DNA Oligomer-12 sets (Wako Pure Chemical Industries, Osaka, Japan) were used. Nucleotide sequences of the primers are presented in Table S1 of the Electronic Supplementary Material. For amplification, a $20-\mu \mathrm{L}$ PCR mixture containing $20 \mathrm{ng}$ fungal genomic DNA, $100 \mathrm{pmol}$ of primer, and $10 \mu \mathrm{L}$ of Premix Ex Taq Hot Start Version (Takara Bio) was prepared. The following PCR program was used for RAPD analyses: $95^{\circ} \mathrm{C}$ for $5 \mathrm{~min} ; 40$ cycles of $95^{\circ} \mathrm{C}$ for $1 \mathrm{~min}, 40^{\circ} \mathrm{C}$ for $1 \mathrm{~min}$, and $72^{\circ} \mathrm{C}$ for $2 \mathrm{~min}$; and $72^{\circ} \mathrm{C}$ for $5 \mathrm{~min}$. Amplified products were separated on a $2 \%(\mathrm{w} / \mathrm{v})$ agarose gel containing $1 \times$ Tris-acetate-EDTA (TAE), then stained with ethidium bromide and observed under UV irradiation.

\section{Results}

Characteristics of fungi isolated from diseased lettuce

Verticillium wilt caused severe browning and wilt of mature lettuce in upland paddy fields on Awaji Island, Hyogo Prefecture (Fig. 1a). Vascular browning developed at the crown (Fig. 1b) and often at the stem above the crown of the diseased lettuce plants. The fungus isolated from diseased lettuce was identified as $V$. tricorpus based on its morphological and cultural characteristics (Kanto et al. 2003, 2005) including verticillate phialides (Fig. 1d) and the presence of microsclerotia (Fig. 1c, g), dark resting hyphae (Fig. 1f, g), and chlamydospores (Fig. 1e, g). However, the three types of resting structures were not always formed simultaneously. Often, only one or two kinds of resting structures were observed in one culture. Mature cultures often developed yellow pigmentation. The morphology of strain MIH001 was examined in detail as a representative of the Japanese lettuce isolates. The following mean dimensions were obtained, each based on 50 measurements: conidia $6.2 \times 3.3 \mu \mathrm{m}$; dark resting hyphae, $5.8 \mu \mathrm{m}$ (width); microsclerotia, $91.2 \times 46.7 \mu \mathrm{m}$; chlamydospores, $7.7 \times 6.4 \mu \mathrm{m}$. 

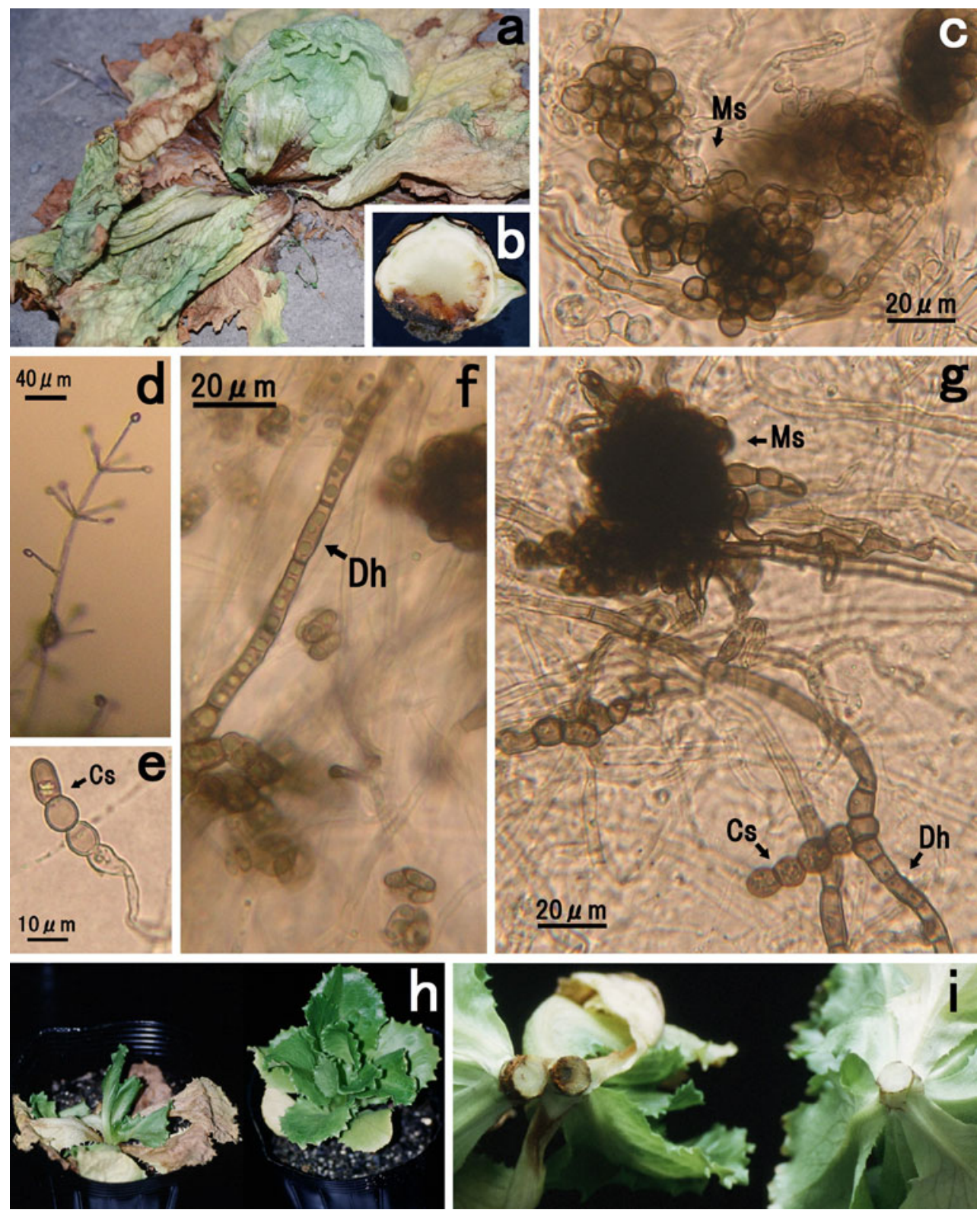

Fig. 1 a Verticillium wilt on lettuce in an upland paddy field in Awaji Island, Hyogo Prefecture. b Vascular browning at the crown of the diseased lettuce. c Microsclerotia (Ms), d conidiophore, e chlamydospores (Cs), and $\mathbf{f}$ dark resting hyphae (Dh) of strain MIH001. g Microsclerotium (Ms), chlamydospores (Cs), and dark resting hyphae (Dh) of strain MIH003. h Seedlings of lettuce cv. Santos-2

\section{Pathogenicity tests}

During six pathogenicity tests using the Japanese lettuce isolate MIH001 (Table 2), typical wilting and vascular browning at the crown developed (Fig. 1h, i). Although wilting scores of 1-3 were recorded for several seedlings inoculated with strain MIH001, no seedlings had a wilting score of 4. Verticillium tricorpus was reisolated from symptomatic lettuce seedlings. inoculated with strain MIH001 (left, wilting score = 3) and noninoculated control (right) in a pathogenicity test (experiment 5). i Cross sections at crown of lettuce cv. Santos-2 inoculated with strain MIH001 (left) and noninoculated control (right) in a pathogenicity test (experiment 5)

DNA sequencing analyses

Nucleotide sequences determined in this study were registered with GenBank/EMBL/DDBJ database (http://www. ddbj.nig.ac.jp/index-e.html). Sequences of the ITS1-5.8SITS2 region, $E F 1 \alpha$ and $r p b 1$ of each strain are available as accessions AB545875-AB545895, AB545897-AB545906, AB545911-AB545921, AB545923, and AB548747AB548758. 
Table 2 Results of experiments (Exp.) to test the pathogenicity of Verticillium tricorpus MIH001 on lettuce cultivars

\begin{tabular}{|c|c|c|c|c|c|}
\hline Cultivar & Exp. & Inoculation & Wilted plants $(\%)^{\mathrm{a}}$ & Average wilt severity & Vascular browning $(\%)^{\mathrm{b}}$ \\
\hline \multirow[t]{4}{*}{ Logic } & \multirow[t]{2}{*}{$1^{\mathrm{c}}$} & MIH001 & 78.6 & 1.4 & 85.7 \\
\hline & & None & 0.0 & 0.0 & 0.0 \\
\hline & \multirow[t]{2}{*}{$2^{\mathrm{d}}$} & MIH001 & 100.0 & 1.6 & 100.0 \\
\hline & & None & 0.0 & 0.0 & 0.0 \\
\hline \multirow[t]{4}{*}{ Cisco } & \multirow[t]{2}{*}{$3^{\mathrm{e}}$} & МIH001 & 50.0 & 0.8 & 66.7 \\
\hline & & None & 0.0 & 0.0 & 0.0 \\
\hline & \multirow[t]{2}{*}{$4^{\mathrm{d}}$} & MIH001 & 100.0 & 1.4 & 57.1 \\
\hline & & None & 0.0 & 0.0 & 0.0 \\
\hline \multirow[t]{4}{*}{ Santos-2 } & \multirow[t]{2}{*}{$5^{\mathrm{f}}$} & MIH001 & 83.3 & 1.2 & 66.7 \\
\hline & & None & 0.0 & 0.0 & 0.0 \\
\hline & \multirow[t]{2}{*}{$6^{\mathrm{g}}$} & MIH001 & 100.0 & 1.5 & 100.0 \\
\hline & & None & 0.0 & 0.0 & 0.0 \\
\hline
\end{tabular}

${ }^{a}$ Percentage of wilted plants

${ }^{\mathrm{b}}$ Percentage of plants with vascular browning in cross and vertical sections of taproot and stem

${ }^{c}$ Fourteen seedlings were used for each treatment. Symptoms were evaluated at $25 \mathrm{~d}$ after inoculation (dai)

${ }^{d}$ Seven seedlings were used for each treatment. Symptoms were evaluated at 33 dai

e Twelve seedlings were used for each treatment. Symptoms were evaluated at 28 dai

${ }^{f}$ Twelve seedlings were used for each treatment. Symptoms were evaluated at 18 dai

g Four seedlings were used for each treatment. Symptoms were evaluated at 33 dai

Phylogenetic analyses

The maximum parsimony (MP) tree derived from combined nucleotide sequences of the ITS1-5.8S-ITS2 region, $E F 1 \alpha$, and $r p b 1$ is presented in Fig. 2. Although two different methods [MP and neighbor-joining (NJ)] were used to derive the trees, the topologies of the trees were identical. The nucleotide sequences that we analyzed were identical among the eight Japanese lettuce isolates, except for two nucleotides in rpbl. No difference was found among the nucleotide sequences of American lettuce isolates and strain NBRC 31025. In contrast, the sequences differed significantly between Japanese and American lettuce isolates in all three genetic regions. Strains MIH001 and Ls.183 differed in 4 nucleotides (nt) for ITS1-5.8SITS2 (433 bp), $7 \mathrm{nt}$ for $E F 1 \alpha$ (436 bp), and 9 nt for $r p b 1$ (632 bp). Nucleotide sequences of the ITS1-5.8S-ITS2 region and $E F 1 \alpha$ were identical among Japanese delphinium isolates and indistinguishable from those of American lettuce isolates. However, the rpbl sequence differed between the Japanese delphinium isolates and the American lettuce isolates. In comparison with the American lettuce isolates, Japanese delphinium isolates from Miyagi Prefecture (MAFF 712235 and MAFF 712236) and an isolate from Kagawa Prefecture (NO-1) differed in 7 and 2 nt. Consequently, of the three genomic regions analyzed, $r p b 1$ appeared to have differed the most. Japanese isolates from solanaceous plants (CE98Vt1 from potato and

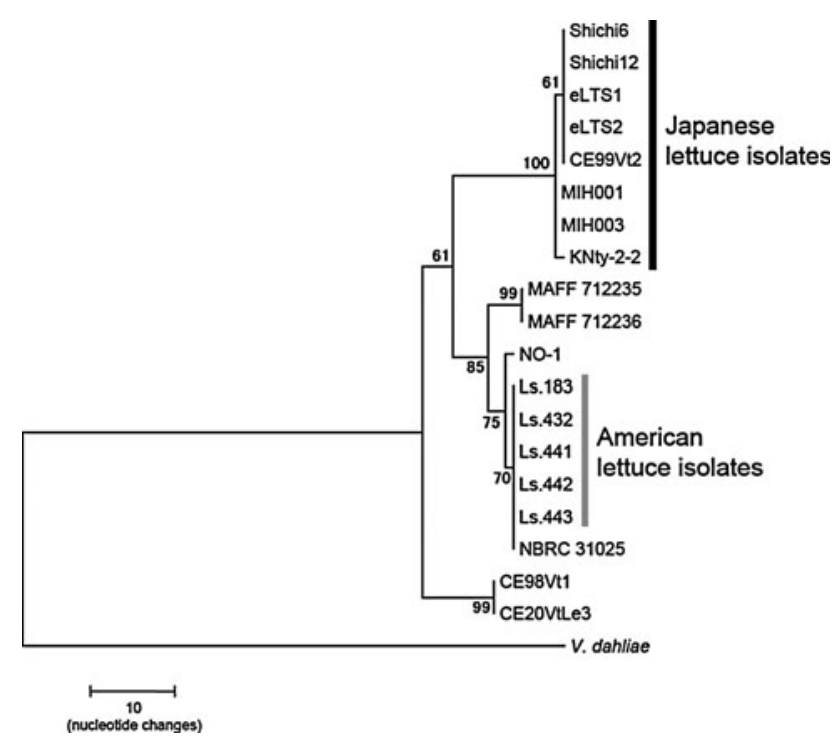

Fig. 2 A maximum parsimony tree derived from the combined nucleotide sequences of ITS1-5.8S-ITS2 region, $E F 1 \alpha$, and $r p b 1$. Bootstrap values (1,000 replicates) are indicated on branches. Vertical bars indicate Japanese and American lettuce isolates, respectively. All other ingroup isolates are Verticillium tricorpus from non-lettuce hosts. V. dahliae strain TV103 was used as the outgroup

CE20VtLe3 from tomato) were distinguishable from other isolates by the sequence of the ITS1-5.8S-ITS2 region and $r p b 1$. Their $E F 1 \alpha$ sequences were identical to that of the American lettuce isolates. 
RAPD analyses

As examples, the RAPD patterns with primers E10, G21, C52 and D62 are shown in Fig. 3. With all 16 primers used, banding patterns of Japanese lettuce isolates were clearly similar to each other and specific to these isolates. Banding patterns of American lettuce isolates were also mutually similar. Although the non-lettuce strains NBRC 31025, MAFF 712235, MAFF 712236, and NO-1 tended to have patterns similar to that of American lettuce isolates, some differences were observed. In the Japanese isolates obtained from delphinium, banding patterns differed between isolates from Miyagi Prefecture (MAFF 712235 and MAFF 712236) and an isolate from Kagawa Prefecture (NO-1). In addition, patterns for Japanese isolates from solanaceous plants (CE98Vt1 from potato and CE20VtLe3 from tomato) resembled each other, differing from all other banding patterns. The similarities in these banding patterns correlated well with the groups obtained in the phylogenetic tree (Fig. 2). These results demonstrated that, regardless of the primer pair used, banding patterns always differed between the Japanese and American lettuce isolates.
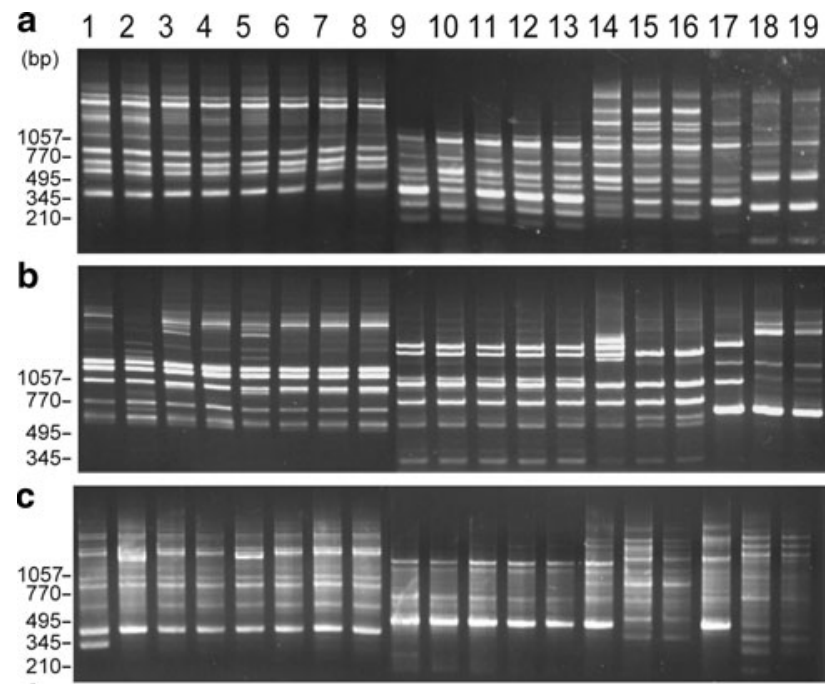

d

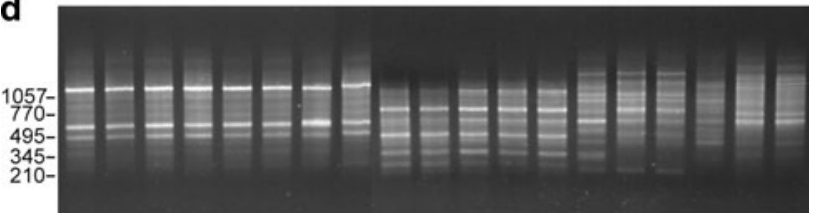

Fig. 3 Random amplified polymorphic DNA (RAPD) analysis of Verticillium tricorpus using four primers: a primer E10, b primer G21, c primer C52, d primer D62. Lanes 1-8 are Japanese lettuce isolates (MIH001, MIH003, Shichi6, Shichi12, KNty-2-2, CE99Vt2, eLTS1, and eLTS2). Lanes 9-13 are American lettuce isolates (Ls.183, Ls.432, Ls.441, Ls.442, and Ls.443). Lanes 14-19 show data for non-lettuce isolates (NBRC 31025, MAFF 712235, MAFF 712236, NO-1, CE98Vt1, and CE20VtLe3)

\section{Discussion}

Isolates of $V$. tricorpus capable of infecting lettuce were first reported in the USA (Qin et al. 2008) followed by Japan (Kanto et al. 2003, 2005). The results of this study clearly demonstrate that the isolates of $V$. tricorpus from lettuce in Japan differed genetically from those collected in the USA. The Verticillium wilt on lettuce caused by $V$. tricorpus in Japan was therefore unrelated to the isolates causing the disease in California.

The genus Verticillium contains several important vascular wilt pathogens, but $V$. tricorpus is generally not considered one of them. In California, V. tricorpus was reported as a weak pathogen on lettuce (Qin et al. 2008). However, V. tricorpus strain MIH001, obtained from diseased lettuce in Japan, was quite severe on some cultivars of lettuce (Table 1). Other Japanese isolates, except for three strains from Chiba Prefecture (eLTS1, eLTS2, and CE99Vt2) were as severe as MIH001 on lettuce cultivars (Kanto et al. 2003, 2005; data not shown). Seedlings infected by Japanese lettuce isolates developed both vascular browning and foliar wilting. The relatively severe symptoms caused by the Japanese $V$. tricorpus isolates in the field might be due in part to the particular environmental conditions. As opposed to the dry growing conditions prevalent in California, lettuce is often planted in very moist environments such as the upland paddy fields in Hyogo Prefecture in Japan. We are therefore unable to speculate about any potential differences in virulence between American and Japanese lettuce isolates without additional pathogenicity tests using isolates from both countries under identical conditions. Such studies may also offer clues to the conditions that may cause a generally weak pathogen on most hosts (Qin et al. 2008) to be came a pathogen of serious agricultural importance.

The differences in virulence between the Japanese and California isolates of $V$. tricorpus could also be due to genetic differences. Even though the isolates of both groups had morphologically similar resting structures, like those of the California isolates of $V$. tricorpus described by Qin et al. (2008), the nucleotide sequences of the three sequenced regions differed significantly, as did their RAPD profiles. Phylogenetic analyses of the combined data from the ITS1-5.8S-ITS2 region and $E F 1 \alpha$ and $r p b 1$ showed that Japanese and American lettuce isolates clustered into two separate clades. The eight Japanese isolates differed by only two substitutions and received maximal bootstrap support. The California isolates and an isolate from an unknown host from the UK were identical at the three loci sequenced, differed from a delphinium isolate from Japan by only two substitutions, and were part of a well-supported clade together with two additional Japanese delphinium isolates. Two $V$. tricorpus isolates included from 
potato and tomato isolated in Japan, formed a separate group differing from all other $V$. tricorpus isolates by at least 20 substitutions. The results from phylogenetic analyses were consistent with the RAPD data. All the RAPD banding patterns differed greatly between American and Japanese lettuce isolates, confirming that Japanese isolates are genetically distinguishable from American isolates.

These data clearly showed that the Japanese and California lettuce isolates included here represent two genetically different groups. We can thus rule out contaminated seed from California as the source for the Verticillium wilt outbreak of lettuce investigated here. Another important finding of this study is the high diversity within V. tricorpus, in agreement with Korolev and Katan (1999), who found considerably more vegetative compatibility groups in $V$. tricorpus than in other Verticillium species. Future studies will focus on comparing the virulence of the Japanese and the California isolates, as well as on further exploring the genetic diversity within $V$. tricorpus.

Open Access This article is distributed under the terms of the Creative Commons Attribution Noncommercial License which permits any noncommercial use, distribution, and reproduction in any medium, provided the original author(s) and source are credited.

\section{References}

Atallah ZK, Maruthachalam K, du Toit L, Koike ST, Davis RM, Klosterman SJ, Hayes RJ, Subbarao KV (2010) Population analyses of the vascular plant pathogen Verticillium dahliae detect recombination and transcontinental gene flow. Fungal Genet Biol 47:416-422

Chikuo Y, Hagiwara H, Kimijima E, Kikuchi O, Takahashi T, Izutsu S (2000) Verticillium wilt of Delphinium sp. caused by Verticillium tricorpus (Abstract in Japanese). Jpn J Phytopathol 66:303

Ebihara Y, Nagao H, Uematsu S, Moriwaki J, Kimishima E (2003) First report of Verticillium tricorpus isolated from potato tubers in Japan. Mycoscience 44:481-488

Isaac I (1953) A further comparative study of pathogenic isolates of Verticillium: V. nubilum Pethybr. and V. tricorpus sp. nov. Trans Br Mycol Soc 36:180-195
Isaac I (1967) Speciation in Verticillium. Annu Rev Phytopathol 5:201-222

Kanto T, Aino M, Maekawa K, Tanaka H (2003) The first occurrence of Verticillium wilt on lettuce in Japan (Abstract in Japanese). Jpn J Phytopathol 69:63

Kanto T, Usami T, Ebihara Y, Maekawa K, Aino M (2005) Identification of pathogens of lettuce Verticillium wilt (Abstract in Japanese). Jpn J Phytopathol 71:214-215

Korolev N, Katan T (1999) Vegetative compatibility grouping in Verticillium nigrescens and V. tricorpus. Mycol Res 103:65-76

Pantou MP, Strunnikova OK, Shakhnazarova VY, Vishnevskaya NA, Papalouka VG, Typas MA (2005) Molecular and immunochemical phylogeny of Verticillium species. Mycol Res 109:889-902

Pegg GF, Brady BL (2002) Verticillium wilts. CAB International, Oxford

Qin QM, Vallad GE, Subbarao KV (2008) Characterization of Verticillium dahliae and $V$. tricorpus isolates from lettuce and artichoke. Plant Dis 92:69-77

Rehner SA, Buckley E (2005) A Beauveria phylogeny inferred from nuclear ITS and EF1- $\alpha$ sequences: evidence for cryptic diversification and links to Cordyceps teleomorphs. Mycologia 97:84-98

Smith HC (1965) The morphology of Verticillium albo-atrum, $V$. dahliae and V. tricorpus. N Z J Agric Res 8:450-478

Tamura K, Dudley J, Nei M, Kumar S (2007) MEGA4: Molecular Evolutionary Genetics Analysis (MEGA) software version 4.0. Mol Biol Evol 24:1596-1599

Thompson JD, Higgins DG, Gibson TJ (1994) CLUSTAL W: improving the sensitivity of progressive multiple sequence alignment through sequence weighting, position-specific gap penalties and weight matrix choice. Nucleic Acids Res 22:4673-4680

Usami T, Abiko M, Shishido M, Amemiya Y (2002) Specific detection of tomato pathotype of Verticillium dahliae by PCR assays. J Gen Plant Pathol 68:134-140

Usami T, Shishido M, Ebihara Y, Kamigahira Y, Amemiya Y (2005) Retrotransposon-like elements in the genome of Verticillium dahliae may be used as DNA markers for fungal species and pathotypes. J Gen Plant Pathol 71:117-123

Vallad GE, Bhat RG, Koike ST, Ryder EJ, Subbarao KV (2005) Weedborne reservoirs and seed transmission of Verticillium dahliae in lettuce. Plant Dis 89:317-324

White TJ, Bruns T, Lee S, Taylor J (1990) Amplification and direct sequencing of fungal ribosomal RNA genes for phylogenetics. In: Innis MA, Gelfand DH, Sninsky JJ, White TJ (eds) PCR protocols: a guide to methods and applications. Academic Press, San Diego, pp 315-322 